\title{
Possíveis cedências do controle da administração no pós-pandemia
}

Possible assignments of post-pandemic administration control

Alan José de Oliveira Teixeira ${ }^{1}$

\section{RESUMO}

Em 2020, com a pandemia da Covid-19, países como o Brasil adotaram um regime jurídico próprio para o enfrentamento da crise sanitária, com a flexibilização de contratações públicas e divisão dialogada de competências entre os entes federados. Preocupa, no entanto, os parâmetros de controle para os atos administrativos, atos da administração e as decisões públicas no cenário posterior à crise de saúde. O presente artigo estuda possíveis cedências do controle da administração pública no cenário pós -pandemia (Covid-19). Para isso, realizou-se um estudo eminentemente bibliográfico, abrangendo a análise de livros e artigos científicos sobre o tema, bem como uma investigação dos textos jurídicos-normativos de regência no período e decisões judiciais pertinentes ao objeto pesquisado. Ao final, chegou-se à conclusão de que o controlador deve realizar um exercício de empatia com o gestor público da época, não significando um abandono da legalidade, que no cenário abrange a necessidade de que as decisões administrativas tenham sido efetuadas com base em evidências científicas.

Palavras-Chave: Direito Administrativo. Covid-19. Controle da Administração. Evidências Científicas.

\footnotetext{
1 Mestrando em Direito (Poder, Estado e Jurisdição) pelo Centro Universitário Internacional (Uninter) na qualidade de bolsista de produtividade em pesquisa do Programa de Pós-Graduação Stricto Sensu em Direito (PPGD), sob orientação do professor doutor Daniel Ferreira. Membro da Red Iberoamericana Juvenil de Derecho Administrativo (RIJDA) e do grupo de pesquisa "A administração pública brasileira e seus controles na perspectiva da sociedade global, tecnológica e de risco e mediante consideração de inovações tecnológicas disruptivas”, vinculado ao PPGD-Uninter. E-mail: alanjose2011@live.com
} 


\section{ABSTRACT}

In 2020, with the Covid-19 pandemic, countries like Brazil adopted their own legal regime to face the health crisis, with the flexibility of public contracts and a dialogical division of competences between the federated entities. However, it concerns the control parameters for administrative acts, administration acts and public decisions in the scenario after the health crisis. This article studies possible cessions in the control of public administration in the post-pandemic scenario (Covid-19). To this end, an eminently bibliographic study was carried out, covering the analysis of books and scientific papers on the subject, as well as an investigation of the legal-normative texts of the period and judicial decisions relevant to the object under study. In the end, it was concluded that the controller must perform an exercise of empathy with the public manager at the time, not meaning an abandonment of legality, which in the scenario encompasses the need for administrative decisions to be made based on evidence scientific.

Keywords: Administrative Law. Covid-19. Management Control. Scientific Evidence.

Recebido: 20-07-2020

Aprovado: 13-10-2020

\section{INTRODUÇÃO}

Em 2020, ano em que se iniciava uma nova década, o mundo não imaginava uma crise sanitária provocada pelo novo coronavírus (Covid-19). Com a decretação de pandemia pela Organização Mundial da Saúde (OMS), as recomendações pelo isolamento social influenciaram muitos países e seus governos locais a determinarem o fechamento temporário de comércios e atividades não essenciais. No Brasil, estados e municípios tomaram a frente na edição de medidas de enfrentamento à 
doença. Em consequência disso, locais que reúnem um grande contingente de pessoas como concertos musicais, shoppings, casas noturnas etc. foram fechados ou tiveram suas atividades e pessoal reduzidos. Diversas empresas adotaram o regime de home office. O governo brasileiro, na esteira dos demais países do mundo, adotou uma legislação específica para o combate da pandemia. Preocupa, juridicamente, os parâmetros e a intensidade do controle exercido no cenário pós-pandêmico, haja vista a inexistência de parâmetros jurisprudenciais para a situação emergencial, que novidade completa.

Nesse cenário, este trabalho tem como escopo investigar possíveis cedências do controle da Administração no cenário pós-pandemia. Para tal, pretendeu-se uma pesquisa bibliográfica na qual se dissertou acerca do tema, com o apoio de livros e artigos científicos pertinentes, assim como a pesquisa de julgados e a legislação vigente. Inicialmente, trabalha-se com o regime jurídico da pandemia, notadamente se tratando de contratações “emergenciais”, regulação sanitária e a imposição de sanções administrativas. Posteriormente, o controle da administração e suas cedências possíveis são averiguadas para, ao final, tecerem-se algumas conclusões.

\section{O REGIME JURÍDICO DA PANDEMIA: CONTRATAÇÕES “EMERGENCIAIS", REGULAÇÃO SANITÁRIA E A IMPOSI- ÇÃO DE SANÇÕES}

No dia 30 de janeiro de 2020 a OMS declarou o surto do novo coronavírus (Sars-CoV-2) como Emergência de Saúde de Importância Internacional (ESPII) (OPAS BRASIL, 2020). Em 11 de março, o estado de contaminação foi elevado à categoria de pandemia (UNA-SUS, 2020).

No Brasil, o Decreto Legislativo 6 de 2020 reconheceu a ocorrência do estado de calamidade pública, dispensando o atingimento dos resultados fiscais previstos na legislação (BRASIL, 2020d). Além disso, a Lei 
13.979 de 2020 tratou das "medidas para enfrentamento da emergência de saúde pública de importância internacional decorrente do coronavírus responsável pelo surto de 2019" (BRASIL, 2028), complementada pelas Medidas Provisórias 926 e 951 de 2020. Algumas dessas medidas têm incidência no regime de contratação pela Administração Pública.

A regra do regime jurídico administrativo exige que a Administração Pública contrate por meio da licitação (artigo 37, inciso XXI, da CRFB). Como exceção, a licitação pode ser desnecessária em alguns momentos, conforme a Lei 8.666/1993, tais como os casos de licitação dispensada (artigo 17), dispensa de licitação (artigo 24) e de inexigibilidade de licitação (artigo 25).

Antes da publicação da Lei 13.979/2020, a legislação brasileira já previa possibilidade de dispensa de licitação por emergência ou calamidade no artigo 24, inciso IV, da Lei 8.666/1993.

Diogo de Figueiredo Moreira Neto e Flávio Garcia (2014, p. 158) compreendem que a contratação emergencial é "um instrumento posto à disposição do administrador público com vistas a garantir fundamentalmente: o direito à vida $\mathrm{e} a$ incolumidade das pessoas e a proteção ao patrimônio público e privado".

Marçal Justen Filho (2012, p. 348), comentando o aventado inciso IV do artigo 24 da Lei 8.666/1993, aduz: "Deve destacar-se que as situações reconduzíveis à hipótese do in. IV não são idênticas entre si. Em todos os casos, a emergência significará a impossibilidade de aguardar o decurso do prazo normal da licitação".

O autor compara o instituto das contratações emergenciais com o da requisição administrativa (JUSTEN FILHO, 2012, p. 348), instituto que tem protagonizado discussões a respeito da possibilidade de requisições de leitos por estados e municípios para combater a pandemia (vide ADI 6362). No Brasil, trabalhos como os de Tulio César Pereira Machado Martins já defendiam a legalidade da aquisição de medicamentos e insumos 
para tratamento médico mediante contratação emergencial (MARTINS, 2013).

Todavia, a dispensa prevista pela nova legislação não é idêntica: a dispensa da Lei 13.979/2020 é específica para aquisição de bens, serviços, inclusive de engenharia, e insumos destinado ao enfrentamento da emergência de saúde pública de importância internacional decorrente do coronavírus (REIS; ALCÂNTARA, 2020). De acordo com Luciano Reis e Marcos Alcântara (2020, p. 5), a hipótese da Lei se trata de uma "dispensa de licitação por situação calamitosa, porém com fundamento legal e requisitos distintos da "dispensa por emergência ou calamidade geral" da Lei $n^{\circ} 8.666 / 93$ ". O legislador criou, portanto, uma hipótese nova de dispensa de licitação.

É importante registrar que a dispensa de licitação em apreço é possível para o enfrentamento da emergência de saúde pública de importância internacional decorrente do coronavírus (artigo $4^{\circ}$, caput), ou seja, este é o seu pressuposto de fato e de direito e, assim, o motivo da decisão administrativa de dispensa. De outro vértice, a motivação, por definição, exige mais especificidade, o que quer significar que o agente público precisa demonstrar no ato administrativo a afetação direta com a situação de crise sanitária, necessidade e adequação, além de inexistência de outros meios.

Corrobora o entendimento esposado o Tribunal de Contas da União, que no Acórdão 1335/2020, do Plenário, proferiu a seguinte decisão colegiada no Relatório de Acompanhamento TC 014.575/2020-5, de relatoria do Ministro Benjamin Zymler:

ACORDAM os Ministros do Tribunal de Contas da União, reunidos em sessão do Plenário, ante as razões expostas pelo Relator em: [...] 9.1. determinar ao Ministério da Saúde que: [...] 9.1.2. com fundamento no art. $4^{\circ}-\mathrm{E}, \S 1^{\circ}$, da Lei 13.979/2020, instrua os processos de contratação relacionados ao enfrentamento da crise do novo coronavírus com a devida motivação dos atos por meio da inclusão nos autos, no mínimo, de justificativas específicas da necessidade da contratação, da quan- 
tidade dos bens ou serviços a serem contratados com as respectivas memórias de cálculo e com a destinação do objeto contratado (BRASIL, 2020c, grifos nossos).

Isto é, a legislação previu inexigência de estudos preliminares para contratação de bens e serviços comuns e possibilidade de apresentação de termo de referência e projeto básico simplificados (artigos $4^{\circ}-\mathrm{C}$ e $4^{\circ}$-E). E, para a corte de contas brasileira, tanto as "justificativas específicas da necessidade de contratação" como a "quantidade dos bens ou serviços a serem contratados" - estes acompanhados das memórias de cálculo e destinação do objeto contratado - são aspectos integrantes da motivação da decisão administrativa com base no artigo $4^{\circ}$-E da Lei 13.979/2020.

Outrossim, o artigo $4^{\circ}$-B, inserido pela MPV 926/2020, pressupõe que a dispensa admitida na Lei atende aos requisitos de: situação de emergência, necessidade de pronto atendimento, existência de risco à segurança e limitação da contratação ao necessário para atendimento da situação emergencial. Esses são, pois, todos motivos do ato de decisão de dispensa, os quais devem conter a devida motivação.

$\mathrm{O} \S 3^{\circ}$ do artigo $4^{\circ}$ autoriza, em caráter excepcional, a contratação de fornecedor inidôneo ou com o direito de participar de licitação/contratar com o poder público suspenso - quando este for o único fornecedor. Ademais, o artigo $4^{\circ}$-A, inserido pela MPV 926/2020, permite que a aquisição de bens e contratação de serviços não se limite a equipamentos novos, sob a condição de responsabilidade do fornecedor.

Há hipótese de flexibilização do atendimento ao requisito de regularidade fiscal e trabalhista (artigo $4^{\circ}-\mathrm{F}$ ), além de redução, à metade, dos prazos da modalidade licitatória de pregão, seja presencial ou seja eletrônico (artigo $4^{\circ}-\mathrm{G}$ ) e dispensa da realização de audiência pública (artigo $\left.4^{\mathrm{o}}-\mathrm{G}, \S 3^{\circ}\right)$.

Temas de Direito Público e igualmente objeto de decisões administrativas são a regulação sanitária e a imposição de sanções administrativas. 
O Direito Regulatório ou Direito da Regulação é um ramo do Direito Público (ARANHA, 2018). Todavia, o Direito da Saúde, a exemplo, mescla tradicionais ramos do conhecimento jurídico (Direito Constitucional, Administrativo, dentre outros) com a disciplina jurídica regulatória específica de cada setor, o que permite a composição de um quadro mais apropriado do regramento jurídico que incide sobre determinado setor de atividades reguladas (ARANHA, 2018). Segundo Marcio Aranha (2018), "o diferencial do direito regulatório, enquanto direito de caráter amplo abrangente de diversos setores de atividades relevantes encontra-se fora das atividades mesmas que regula".

Ao se estudar a regulação sanitária, está-se a falar de Direito Regulatório. As formas de regulação são, basicamente, regulação operacional (intensidade de avocação do Estado em desempenhar certas atividades) e regulação normativa (ampliação ou restrição de atividades alcançadas por regramento estatal) (ARANHA, 2018). De acordo com Mauricio Aranha (2018), a tendência é de regulação normativa centralizada, mas remetida a autoridades administrativas. O jurista assevera que a regulação, enquanto regime jurídico regulatório, "[...] apresenta-se como um conjunto de disposições normativas e administrativas caracterizadas por seu caráter conjuntural de influência ou controle sobre o ambiente regulado [...]" (ARANHA, 2018). Concebe Aranha (2018) que

O regime jurídico regulatório transparece o conjunto de produções não só normativas, mas administrativas de diuturna reconfiguração do ambiente regulado, como também do formato estatal de ataque aos problemas nele detectados, entendida a indispensabilidade de atuação estatal no que se refere à preservação dos princípios do serviço público, mediante políticas regulatórias ínsitas aos princípios jurídicos inscritos na ideologia constitucionalmente adotada.

A regulação sanitária, porquanto afeta à saúde, cuida-se de uma regulação setorial (ARANHA, 2018). No Brasil, as agências reguladoras 
possuem um papel relevantíssimo na regulação. O modelo brasileiro de agências reguladoras

assimila, em uma mesma estrutura administrativa, duas formas de regulação de setores, quais sejam: controle de andamento de atividades setoriais pelas agências; transferência da prestação dos serviços públicos de um determinado setor para empresas privadas e sua consequente regulação por intermédio de contratos administrativos acompanhados pari passu por estruturas dotadas de conhecimento técnico (ARANHA, 2018).

De acordo com Christiane Maia e Dirce Guilhem (2016, p. 226), a "regulação traduz-se no modo de ação do Estado para evitar que práticas em determinado setor econômico ou social variem além de certos limites preestabelecidos". As pesquisadoras afirmam que, em saúde pública, a regulação sanitária se justifica pelo seguinte:

1) o fato de que a ausência de intervenção do Estado pode implicar em riscos para outras pessoas além daquela que utiliza os bens e serviços; 2) a necessidade de proteção para os mais vulneráveis; e 3 ) o controle dos riscos ao próprio consumidor, em especial quando esse risco já está socialmente incorporado e causa danos significativos, como é o caso do tabagismo (2) (MAIA; GUILHEM, 2016, p. 226).

Assim, não há como tratar de regulação sanitária sem mencionar a existência de competências estabelecidas pelo Sistema Nacional de Vigilância Sanitária para a atuação da Agência Nacional de Vigilância Sanitária (Anvisa). Como se sabe, cabe à Anvisa a edição de normas e a autuação e aplicação das penalidades previstas em lei, admitindo-se a delegação de certas atribuições a municípios, estados e Distrito Federal (BRASIL, 1999. art. 27, inciso III, XXIV e $\S 1^{\circ}$ ).

Mas, em tempos pandêmicos, determinadas legislações ainda vigentes e criadas para fins específicos e emergências sanitárias são um nor- 
te interessante na regulação e aplicação de sanções administrativas pelo poder público. Trata-se das Leis 6.259/1975 (“dispõe sobre a organização das ações de Vigilância Epidemiológica, sobre o Programa Nacional de Imunizações, estabelece normas relativas à notificação compulsória de doenças”) e 6.437/1977 (“configura infrações à legislação sanitária federal, estabelece as sanções respectivas"). Aparentemente, muito embora as Leis utilizem a terminologia "epidemia" em sua redação, são plenamente aplicáveis à situação de calamidade pública vivida hoje no Brasil.

$\mathrm{O}$ art. $1^{\circ}$ da Lei 6.259/1975 afirma que compete ao Ministério da Saúde:

o controle das doenças transmissíveis, orientando sua execução inclusive quanto à vigilância epidemiológica, à aplicação da notificação compulsória, ao programa de imunizações e ao atendimento de agravos coletivos à saúde, bem como os decorrentes de calamidade pública (BRASIL, 1975, artigo $1^{\circ}$ ).

E as competências supramencionadas são delegáveis às Secretarias de Saúde dos Estados e do Distrito Federal. $\mathrm{O}$ artigo $7^{\circ}$ faz referência à possibilidade de quarentena, isolamento e notificação compulsória - estratégia implementada por muitos países (inclusive o Brasil) no combate à Covid-19.

Ademais, em 2018 a Lei 6.259/1975 foi alterada para, no artigo 14, nova redação considerar infração sanitária a inobservância das obrigações nela estabelecidas. A Lei que cuida das infrações à legislação sanitária federal é a 6.437/1977, a qual o texto normativo prevê as seguintes punições: advertência, multa, apreensão de produto, interdição parcial ou total do estabelecimento, cancelamento de autorização para funcionamento de empresa ou estabelecimento, intervenção no estabelecimento que receba recursos públicos de qualquer esfera, imposição de mensagem retificadora, suspensão de propaganda e publicidade etc. (BRASIL, 1977). 
A questão da competência para regulação sanitária foi inclusive objeto de questionamento na Ação Direta de Inconstitucionalidade 6341, por meio da qual decisão monocrática proferida pelo Ministro Marco Aurélio Mello - e referendada pelo Plenário - entendeu pela competência concorrente entre os entes federativos para legislar sobre saúde pública (conforme artigo 23, inciso II, da CRFB), tendo a Lei 13.979/2020 tratado de atribuições das autoridades em relação às medidas a serem implementadas em virtude da pandemia (BRASIL, 2020d). A respeito do tema, Medina e Medina (2020, p. 3) construíram o seguinte:

A todos eles [os entes federativos] incumbe cuidar, proteger e
defender a saúde. Um ente invadirá a competência do outro,
p.ex., se a União dispuser sobre pormenor local, ou se um muni-
cípio estabelecer uma restrição geral de alcance nacional. Não
contraria a Constituição, no entanto, o decreto que dispõe sobre
minúcias locais quanto à proteção à saúde.

O fato é que, sem normas conflitantes entre si, a população já vivencia uma circunstância nova, de incertezas quanto ao emprego, à economia e à saúde. Um Direito Público atual, prospectivo, acolhedor, seguro e eficiente celebra a administração autovinculante, com proibição ao venire contra factum proprium (MOREIRA; PEREIRA, 2018, p. 270) e, acrescente-se: com a devida motivação das decisões públicas.

No que se refere à regulação sanitária, a Lei 13.979/2020 dispôs o seguinte, após a publicação da Lei 14.019/2020:

Art. $3^{\circ}$-G. As concessionárias e empresas de transporte público deverão atuar em colaboração com o poder público na fiscalização do cumprimento das normas de utilização obrigatória de máscaras de proteção individual, podendo inclusive vedar, nos terminais e meios de transporte por elas operados, a entrada de passageiros em desacordo com as normas estabelecidas pelo respectivo poder concedente (Incluído pela Lei $n^{\circ} 14.019$, de 2020). 
Parágrafo único. O poder público concedente regulamentará o disposto neste artigo, inclusive em relação ao estabelecimento de multas pelo seu descumprimento (Incluído pela Lei $\mathrm{n}^{\circ}$ 14.019, de 2020).

Art. $7^{\circ}$. O Ministério da Saúde editará os atos necessários à regulamentação e operacionalização do disposto nesta Lei (BRASIL, 2018).

Isto é, há reiteração da atuação em colaboração com o poder público, notadamente para os fins de regulamentação e fiscalização do cumprimento da obrigatoriedade do uso de máscaras nos terminais e transportes públicos. Além disso, sensível às disposições da Lei 6.259/1975 - na qual o Ministério da Saúde protagoniza maior atuação no combate a epidemias - a Lei 13.979/2020 atribui àquele Ministério a sua regulamentação (artigo $7^{\circ}$ ).

Afigura-se importante neste patamar esclarecer que a expedição de decretos, por parte da Presidência da República, para regulamentar a execução de leis federais, não afasta a competência dos governos estaduais e municipais, presumindo-se, para este fim, a não extrapolação ou o atingimento de interesses mais amplos e gerais (MEDINA; MEDINA, 2020, p. 4).

A aplicação de sanções administrativas mostra-se de relevância ímpar para o Direito Público da pandemia. Pertinente transcrever o que se concebe neste artigo sobre sanções administrativas, que são "[...] a direta e imediata consequência jurídica, restritiva de direitos, de caráter repressivo, determinada pela norma jurídica a um comportamento proibido nela prevista, comissivo ou omissivo, dos seus destinatários" (FERREIRA, 2001, p. 25). Outrossim, somente se admite o seu afastamento em razão de uma justificativa que torne a conduta antinormativa (FERREIRA, 2009, p. 333). Tal justificativa deve ser oriunda da lei (FERREIRA, 2009, p. 64). Isto posto, interessante voltar-se para a Lei 13.979/2020, na qual consta o que segue acerca das sanções administrativas:

Art. $6^{\circ}$-C. Não correrão os prazos processuais em desfavor dos acusados e entes privados processados em processos adminis- 
trativos enquanto perdurar o estado de calamidade de que trata o Decreto Legislativo $\mathrm{n}^{\circ} 6$, de 2020. (Incluído pela Medida Provisória $\mathrm{n}^{\circ}$ 928, de 2020)

Parágrafo único. Fica suspenso o transcurso dos prazos prescricionais para aplicação de sanções administrativas previstas na Lei ${ }^{\circ} 8.112$, de 1990, na Lei $n^{\circ} 9.873$, de 1999, na Lei ${ }^{\circ}$ 12.846, de 2013, e nas demais normas aplicáveis a empregados públicos. (Incluído pela Medida Provisória $n^{\circ} 928$, de 2020)

Art. $6^{\circ}$-D. Fica suspenso o transcurso dos prazos prescricionais para aplicação de sanções administrativas previstas na Lei $\mathrm{n}^{\circ}$ 8.666, de 1993, na Lei $\mathrm{n}^{\circ} 10.520$, de 17 de julho de 2002, e na Lei $\mathrm{n}^{\mathrm{o}} 12.462$, de 4 de agosto de 2011 (Incluído pela Medida Provisória $n^{\circ}$ 951, de 2020).

$\mathrm{O}$ artigo $6^{\circ}$-C parece tratar da suspensão de eventuais prazos em processos administrativos federais que em circunstâncias normais correriam em desfavor dos entes privados e dos acusados, além de suspender, no parágrafo único, prazos para aplicação de sanções administrativas como penalidades disciplinares e as sanções previstas na Lei Geral de Licitações, por exemplo, assim como de responsabilização objetiva da Administração Pública. Cumpre ressaltar que as alterações supra foram inseridas pela MPV 928/2020, que ainda precisará ser convertida em lei, muito embora as regras já estejam em vigor.

Alguns estados foram na mesma linha e suspenderam os prazos nos processos administrativos, como no Paraná; nesse estado com exceção dos casos em que verificada hipótese de prescrição ou decadência (PARANÁ, 2020b). Também no Paraná, a Lei Estadual 20.189/2020, regulamentada pelo Decreto Estadual 5040/2020, prevê a aplicação de multas às pessoas físicas e jurídicas que descumprirem as orientações sanitárias da legislação vigente (PARANÁ, 2020a).

À legislação geral sobre o regime jurídico da pandemia acrescente um aspecto que, nessa nova racionalidade, passa a ser condição de legalidade e constitucionalidade das decisões públicas: a necessidade de que todas as decisões sejam tomadas com base em evidências científicas (art. 
$3^{\mathrm{o}}, \S 1^{\mathrm{o}}$, da Lei $\left.13.979 / 2020\right)$.

Assim, se o gestor municipal entender pela necessidade de lockdown (protocolo mais rígido de isolamento), deve estar munido de fundamentos científicos, evidências, pois a medida não se trata de uma decisão política. Tudo isso leva à reflexão concernente à importância da motivação das decisões administrativas.

\section{O CONTROLE NA PANDEMIA: POSSÍVEIS CEDÊNCIAS}

Neste ponto, cumpre-se salientar que a Administração Pública, no exercício de suas funções, está sujeita a controle pelos poderes Legislativo, Judiciário, além de ela mesma controlar seus atos (DI PIETRO, 2014, p. 880). Isso tendo em vista o ideal de se assegurar uma atuação conforme a lei e aos princípios que a regem (DI PIETRO, 2014, p. 880).

O controle também pode ser interno (exercido sobre seus próprios atos e agentes, como uma Tomada de Contas Especial feita pelo Ministério da Educação) ou externo (um dos poderes sobre o outro, como uma prestação de contas do Município submetida ao Tribunal de Contas do Estado). Outro exemplo de controle externo é o jurisdicional (ação popular, ação civil pública, habeas data, mandado de segurança etc.). Contextualizado o estudo, importante discorrer sobre a Lei 13.655/18 e suas alterações, especialmente o artigo 22.

$\mathrm{O}$ artigo 22 enseja alteridade por parte do controlador, que deve sopesar as dificuldades e obstáculos do gestor na sua atividade administrativa. Deve-se ainda considerar as circunstâncias práticas, natureza, gravidade, danos e a dosimetria de sanções relativas ao mesmo fato.

Eduardo Jordão, estudando o art. 22 da LINDB, argumenta que o dispositivo é um "pedido de empatia" com o gestor público. Há, assim, prevenção na situação de o julgador se colocar na posição de tomar ou substituir decisões administrativas, pois há que se considerar os ônus que 
o administrador enfrenta (JORDÃO, 2018, p. 70).

$\mathrm{O}$ administrativista afirma que tanto o parágrafo único como a cabeça do art. 22 aplicam-se igualmente a controladores e controlados (autotutela dos atos administrativos) (JORDÃO, 2018, p. 71).

Jordão também sustenta que a presença da imposição de "consideração a obstáculos e dificuldades reais" implica o dever de que tais elementos integrem a motivação dos atos administrativos (JORDÃO, 2018, p. 72). Em termos práticos, o jurista aduz que caberia ao controlador estabelecer diálogo com o gestor, ou até mesmo requerer informações, em caso de omissão (JORDÃO, 2018, p. 73).

De toda sorte, afirma que o julgador ainda deverá avaliar se os ditos “obstáculos e dificuldades" são realmente existentes e se houve impacto destes na atividade controlada (JORDÃO, 2018, p. 74). O autor especifica:

É também possível ao controlador considerar, a despeito de se-
rem "reais", as dificuldades apontadas não teriam tido um efeito
tão limitador quanto o gestor alegou. A lei, afinal, não criou um
salvo conduto para o gestor, a quem bastaria mencionar difi-
culdades para ver-se livre do controle sobre seus atos. Ela ape-
nas exigiu uma "consideração" destas dificuldades (JORDÃO,
2018, p. 74).

Os obstáculos, a título de exemplificação, podem ser de natureza temporal, orçamentária e de pessoal, como a falta de verbas, tempo escasso para a execução da ação, déficit de pessoal, deficiências de material de escritório, infraestrutura para o trabalho etc. (JORDÃO, 2018, p. 76).

Assevera o autor que é preciso admitir que as condições em momento variam em todo o país, haja vista que as dificuldades de um município no interior do país são diversas das dificuldades de uma rica capital brasileira (JORDÃO, 2018, P. 76).

Podem ainda as dificuldades se mostrarem jurídicas (a interpretação da legislação pertinente) (JORDÃO, 2018, p. 77). Acerca das possibilidades diante da dificuldade em tela o autor aponta: 
Do lado da administração pública, duas são as medidas possíveis. A primeira possibilidade, aberta às autoridades superiores, é a edição de regulamentos ou súmulas administrativas que determinem uma interpretação específica, aumentando a segurança jurídica dos gestores, na linha do que prevê o art. 30. A segunda possibilidade, aberta ao administrador da ponta na ausência destas medidas citadas acima, é a explicitação da dúvida jurídica encontrada (JORDÃO, 2018, p. 77).

Como se vê, o autor apresenta duas possibilidades para sanar a dificuldade jurídica, quais sejam: a edição de regulamentos ou súmulas que unifiquem a interpretação; ou o esclarecimento da dúvida perante a autoridade superior.

$\mathrm{Na}$ perspectiva do controlador, observa o seguinte: em vez de impor, no caso, a leitura e interpretação jurídica que ele mesmo faria neste contexto de indeterminação, o controlador deverá então cogitar da existência de uma álea de razoabilidade, ou um leque de interpretações

razoáveis, todas as quais lícitas (JORDÃO, 2018, p. 78).

Ou seja, se o ambiente de aplicação da norma abstrata não é sólido, mas, sim, arenoso, deve o controlador levar em conta as demais teses jurídicas (diversas da sua) ao decidir.

Nesse passo, Eduardo Jordão defende que ao controlador impõe-se nesses casos uma posição mais deferente em relação à escolha da administração pública (JORDÃO, 2018, p. 78).

Jordão ensina que existem "graus" de obstaculização, o que quer significar que a dificuldade pode ser factível, mas não suficientemente determinante para impedir o que prescreve o texto normativo (JORDÃO, 2018, p. 80). Ou seja, a aplicação da LINDB no direito público não implica o abandono da legalidade.

Eliminando qualquer pretensão a argumentos topográficos acerca dos termos "os obstáculos e as dificuldades reais do gestor", "as exigências das políticas públicas a seu cargo" e "os direitos dos administrados", 
Jordão concebe que a expressão "sem prejuízo aos direitos dos administrados" equivale a "além dos direitos dos administrados" (JORDÃO, 2018, p. 82).

Em apertada síntese, o estudioso "traduz" o art. 22, que exige que na aplicação de sanções se considere: os danos para a administração, as agravantes, as atenuantes, os antecedentes e outras sanções (de mesma natureza) já aplicadas (JORDÃO, 2018, p. 85).

O diferencial no contexto jurídico ora estudado é a necessidade de que as decisões administrativas sejam fundamentadas com base em evidências científicas, que condição de legalidade e constitucionalidade das decisões jurídicas. Em interpretação analógica da avaliação de Medina, isso vale tanto para as decisões de contratação como para a regulação sanitária:

No caso dos $\S \S 8 .^{\circ}$ e $9 .^{\circ}$ do art. $3 .^{\circ}$ da Lei $13.979 / 2020$, eventual decreto presidencial que deixe de ser realizado com "base em evidências científicas e em análises sobre as informações estratégicas em saúde" ( $§ 1 .^{\circ}$ do art. 3. ${ }^{\circ}$ da Lei 13.979/2020), p.ex., violará o poder de regulamentar, pois atentará contra a lei a ser regulamentada, e, a um só tempo, violará também a Constituição Federal, por contrariar o direito fundamental à saúde (ao qual corresponde, no caso, o dever de que é destinatário também o Presidente da República), isso é, direito a prestações estatais que deem cumprimento aos deveres de cuidado, proteção e defesa da saúde (MEDINA; MEDINA, 2020, p. 4).

O STF, em acórdão do plenário, decidiu o seguinte acerca das decisões públicas pelas medidas sanitárias mais restritivas (isolamento, lockdown):

Vencidos, em parte, os ministros Edson Fachin e Rosa Weber, que deferiram parcialmente a medida cautelar, para conferir interpretação conforme ao inciso II do $\S 7^{\circ}$ do art. $3^{\circ}$ da Lei 13.979/2020, que condiciona a atuação dos gestores locais à autorização do Ministério da Saúde, a fim de explicitar que, nos termos da regra constitucional que preconiza a descentralização 


\section{Entrole}

do Sistema Único de Saúde, e desde que amparados em evidências científicas e nas recomendações da Organização Mundial da Saúde, estados, municípios e DF podem determinar as medidas sanitárias de isolamento, quarentena, exumação, necropsia, cremação e manejo de cadáveres (BRASIL, 2020a).

Isto é, as evidências científicas, o consenso científico mencionado pela legislação tem como parâmetros, por exemplo, as recomendações do Ministério da Saúde e da OMS. São essas as autoridades sanitárias máximas atualmente. Todavia, a terminologia, por ser abrangente, pode autorizar decisões administrativas não necessariamente vinculadas a este consenso científico.

\section{CONCLUSÃO}

Neste trabalho viu-se que o regime jurídico da pandemia flexibilizou diversas regras e entendimentos criados para situações "normais". Existe uma nova e limitada possibilidade de dispensa de licitação, que diversa das contratações emergenciais previstas na lei geral de licitações e contratos administrativos. A nova modalidade é específica para o contexto de pandemia no Brasil, devendo as decisões públicas que optarem pela dispensa externalizar de modo cristalino a pertinência.

A regulação sanitária enseja a aplicação e observância da legislação criada para este fim, que, muito embora em terrae brasilis seja uma legislação de 1975 e criada para os fins de epidemia, facilitou os caminhos da regulação. Outro ponto aventado e afetado à temática da regulação abrange a Lei de Introdução às Normas do Direito Brasileiro - LINDB, que com as alterações de 2018 trouxe novos ônus argumentativos ao controlador, e apresenta dois caminhos para sanar situações de dificuldade jurídica, visando a segurança: a unificação da interpretação por meio da edição de regulamentos ou súmulas ou o esclarecimento da dúvida perante a autoridade superior. 
Observou-se que a imposição de sanções funciona como um meio para que os governos possam exigir determinadas condutas dos indivíduos e/ou atingir resultados positivos de isolamento social que obstaculizem a propagação do nano inimigo atual.

Apesar da sistemática jurídica criada para o ambiente de calamidade na saúde, a Constituição e as leis brasileiras ainda vigem, e por isso devem ser seguidas e respeitadas. A nova LINDB permitiu uma hermenêutica capaz de mediar situações de emergência jurídica vivenciada hoje por conta da pandemia, especialmente em relação ao controle, que já ocorre, mas que terá um papel ainda mais fundamental no ambiente pós-pandemia: o controlador deverá realizar um exercício de empatia com o gestor público encarregado de enfrentar a situação emergencial.

Isso não significa, em nenhum cenário, que deva fazer vista grossa às decisões administrativas que não cumpram o dever de motivação e cotejo preciso com a situação e legislação da conjuntura calamitosa, mas, muito pelo contrário, utilizar tais parâmetros para o controle que será exercido sobre os atos administrativos no cenário vindouro. E, acrescentese: utilizar o consenso científico, as evidências científicas, as pesquisas, as recomendações dos técnicos e especialistas da época para decidir pela legalidade ou não de determinadas decisões administrativas, cujas motivações devem contemplar parâmetros científicos e técnicos, pois não se trata de decisão política.

\section{REFERÊNCIAS}

ARANHA, M. I. Manual de Direito Regulatório: Fundamentos de Direito Regulatório. 4. ed. London: Laccademia Publishing, 2018.

BRASIL. Superior Tribunal de Justiça (5. Turma). ROMS n 19.210-RS. Relator: Min. Felix Fischer, DJU, Brasília, DF, 10 abr. 2006. 
BRASIL. Supremo Tribunal Federal. ADI 6343 MC-Ref/DF. Relator: Min. Marco Aurélio, (ADI-6343). Brasília, DF: STF, 6 maio 2020a.

BRASIL. Supremo Tribunal Federal. Andamentos da ADI 6341/DF. Brasília, DF: STF, 2020b. Disponível em: https://bityli.com/FDjUs. Acesso em: 14 jul. 2020.

BRASIL. Tribunal de Contas da União. Acórdão no 1335/2020. Plenário. Relator: Ministro Benjamin Zymler. Brasília, DF: TCU, 2020c. Disponível em: https://bityli.com/5uDAj. Acesso em: 14 jul. 2020.

BRASIL. Decreto Legislativo $\mathrm{n}^{\mathrm{o}} 6$, de 2020. Reconhece, para os fins do art. 65 da Lei Complementar $n^{\circ}$ 101, de 4 de maio de 2000, a ocorrência do estado de calamidade pública, nos termos da solicitação do Presidente da República encaminhada por meio da Mensagem no $\mathrm{n}^{\circ}$, de 18 de março de 2020. Diário Oficial da República Federativa da União, Brasília, DF, p. 1, 20 mar. 2020 d.

BRASIL. Lei $\mathrm{n}^{\circ} 6.259$, de 30 de outubro de 1975. Dispõe sobre a organização das ações de Vigilância Epidemiológica, sobre o Programa Nacional de Imunizações, estabelece normas relativas à notificação compulsória de doenças, e dá outras providências. Diário Oficial da União, Brasília, DF, 30 out. 1975.

BRASIL, Lei no 6.427, de 20 de agosto de 1977. Configura infrações à legislação sanitária federal, estabelece as sanções respectivas, e dá outras providências. Diário Oficial da União, Brasília, DF, p. 11145, 24 ago. 1977.

BRASIL. Lei n ${ }^{\circ}$ 9.782, de 26 de janeiro de 1999. Define o Sistema Nacional de Vigilância Sanitária, cria a Agência Nacional de Vigilância Sanitária, e dá outras providências. Diário Oficial da União, Brasília, DF, p. 1, 27 jan. 1999. 
BRASIL. Lei ${ }^{\circ} 13.655$, de 25 de abril de 2018. Inclui no Decreto-Lei $n^{\circ}$ 4.657, de 4 de setembro de 1942 (Lei de Introdução às Normas do Direito Brasileiro), disposições sobre segurança jurídica e eficiência na criação e na aplicação do direito público. Diário Oficial da União: seção 1, Brasília, DF, p. 1, 26 abr. 2018.

DI PIETRO, M. S. Z. Direito administrativo. 27. ed. São Paulo: Atlas, 2014.

FERREIRA, D. Alternativas legais à sanção administrativo-ambiental: uma eventual questão de dignidade da pessoa humana e de sustentabilidade da atividade empresarial. Revista Jurídica, Curitiba, n. 22, n. 6, p. 55-75, 2009.

FERREIRA, D. Sanções administrativas. São Paulo: Malheiros, 2001.

FERREIRA, D. Teoria geral da infração administrativa a partir da constituição federal de 1988. Belo Horizonte: Fórum, 2009.

JORDÃO, E. Art. 22 da LINDB - Acabou o romance: reforço do pragmatismo no direito público brasileiro. Revista de Direito Administrativo, Rio de Janeiro, p. 63-92, 2018.

JUSTEN FILHO, M. Comentários à Lei de licitações e contratos administrativos. 15. ed. São Paulo: Dialética, 2012.

MAIA, C; GUILHEM, D. A regulação sanitária brasileira como parte da política de saúde: lacunas e desafios. Revista Panamericana de Salud Pública, Washington, DC, v. 39, n. 5, p. 226-31, 2016. MARTINS, T. C. P. M. Legalidade da aquisição de medicamentos e 
insumos para tratamento médico mediante contratação emergencial. Revista do Tribunal de Contas do Estado de Minas Gerais, Belo Horizonte, p. 137-151, 2013.

MEDINA, J. C. M.; MEDINA, J. M. G. Saúde e contornos do federalismo brasileiro. Bases constitucionais para a solução de conflitos relacionados à pandemia (Covid-19, Coronavírus): breves considerações. Revista dos Tribunais, v. 1017, 2020.

MOREIRA, E. B.; PEREIRA, P. P. Art. 30 da LINDB: O dever público de incrementar a segurança jurídica. Revista de Direito Administrativo, Rio de Janeiro, p. 13-41, nov. 2018.

NETO, D. F. M.; GARCIA, F. A. Desastres naturais e as contratações emergenciais. Revista de Direito Administrativo, Rio de Janeiro, v. 265, p. 149-178, 2014.

OPAS BRASIL. OMS declara emergência de saúde pública de importância internacional por surto de novo coronavírus. OPAS/OMS Brasil, Brasília, DF, 30 jan. 2020. Disponível em: https://bityli.com/et8B1. Acesso em: 8 jul. 2020.

PARANÁ. Decreto 4.692, de 25 de maio de 2020. Regulamenta a Lei Estadual $n^{\circ} 20.189$, de 28 de abril de 2020, que dispõe sobre o uso geral e obrigatório de máscaras de proteção facial no contexto da pandemia da COVID-19 enquanto perdurar o estado de calamidade pública, e medidas correlatas. Diário Oficial do Estado do Paraná, Curitiba, 25 maio 2020a.

PARANÁ. Decreto 5040, de 3 de julho de 2020. Suspende prazos administrativos, em razão da emergência de saúde pública decorrente do Coronavírus COVID-19. Diário Oficial do Estado do Paraná, Curitiba, 3 jul. 2020 b. 
REIS, L. E.; ALCÂNTARA, M. V. Contratação pública extraordinária no período do Coronavírus. São Paulo: Instituto Licitar, 2020. Disponível em: https://bityli.com/QIPVB. Acesso em: 9 jul. 2020.

UNA-SUS. Organização Mundial de Saúde declara pandemia do novo Coronavírus. UNA-SUS, Brasília, DF, 11 mar. 2020. Disponível em: https://bityli.com/tfHDj. Acesso em: 8 jul. 2020. 